\title{
The role of placental gonadotrophins (PMSG and hCG) in pregnancy in the rat
}

\author{
C. S. Bambra and S. Gombe \\ Department of Animal Physiology, Chiromo, University of Nairobi, Kenya
}

\begin{abstract}
Summary. Treatment of rats with anti-PMSG and anti-hCG for 5 days from Days 6, 11 or 16 of pregnancy caused variable necrosis of fetal tissue, the extent of which increased from the chorionic cells to the inner trophoblastic layers with the increase in dose from 4 to $10 \mathrm{mg}$ anti-PMSG. At $10 \mathrm{mg} /$ day, fetal death and resorption were invariable in early to mid-pregnancy, whilst in late pregnancy some litters were carried to term. The main histological change in the corpora lutea was hyperaemia in the anti-PMSGtreated rats. Immunofluorescence studies with conjugates of anti-hCG and anti-PMSG showed sharp localization in the giant and chorionic cell layer at the feto-maternal junction.
\end{abstract}

We conclude that an hCG/PMSG-like substance is produced by rat chorionic cells and that it plays an immunosuppressive role during pregnancy.

\section{Introduction}

Some mammals, e.g. primates and equids, have large quantities of circulating levels of placental gonadotrophins in early pregnancy but there is no satisfactory explanation of the role played by these gonadotrophins. In these species, placental secretion is manifest by the appearance of the hormones in the blood for a short period only of gestation, but production at a placental level might occur in other species and throughout gestation.

The complete fetal resorption in rats caused by treatment with antibodies to LH (Loewit \& Laurence, 1969) has been attributed to luteal regression, determined by the reappearance of $20 \alpha-$ hydroxysteroid dehydrogenase (Loewit, Badawy \& Laurence, 1969) but not by measurement of ovarian and plasma progesterone and oestrogen concentrations.

Amoroso \& Perry (1975) have proposed that placental gonadotrophins, in conjunction with oestrogens, may form an immunosuppressive glycocalyx coat on the fetal membranes, thereby rendering the fetuses safe from maternal immunological attack. A continuous production of the gonadotrophins would be necessary throughout gestation and removal of the 'coat' should render the fetus liable to attack, death and resorption or expulsion.

The purpose of the present investigation was to find out what happens to gestation if the putative production of placental gonadotrophin is neutralized, and to determine whether the ovarian dysfunction precedes the placental changes or vice versa.

\section{Materials and Methods}

\section{Antibody}

Production. The hCG and PMSG (Chorulon and Folligon: Organon, Surrey, U.K.) were dissolved in $0.01 \mathrm{M}$-sodium phosphate-buffered saline ( $\mathrm{pH} \mathrm{7.2)}$ at a concentration of $10 \mathrm{mg} / \mathrm{ml}$. Aliquots of the hormone solutions $(0.3 \mathrm{ml})$ were combined with equal volumes of complete Freund's adjuvant (Difco, Detroit, Michigan) and emulsified by constant mixing. Two male Masai goats (one for each hormone) were injected intramuscularly with $3 \mathrm{mg}$ emulsion in multiple sites on the hind limbs. Booster doses were given after 5 weeks. Two further boosters were given at 10-day intervals with the hormone preparations in incomplete Freund's adjuvant before bleeding. A maximum of $50 \mathrm{ml}$ blood was drawn by jugular venepuncture at one bleeding. 
Purification. Ice-cold $\left(\mathrm{NH}_{4}\right)_{2} \mathrm{SO}_{4}$ solution was added drop by drop to an equal volume of the goat plasma in an ice-bath, mixed and stirred gently for $30 \mathrm{~min}$. After centrifugation at $1500 \mathrm{~g}$ for $15 \mathrm{~min}$, the precipitate was dissolved in minimal quantities of $0.01 \mathrm{M}$-sodium phosphate-buffered saline (pH 7.2) and extensively dialysed against $0.01 \mathrm{M}$-sodium phosphate buffer ( $\mathrm{pH} \mathrm{7.5)} \mathrm{containing} 0.1$ $\mathrm{M}-\mathrm{NaCl}$. After 2 days the globulin mixture was run in an ion-exchange column containing diethyl aminoethyl cellulose (DE-52) pre-equilibrated with $0.01 \mathrm{M}$-sodium phosphate buffer $(\mathrm{pH} 7 \cdot 2$ ) containing $0 \cdot 1 \mathrm{M}-\mathrm{NaCl}$.

The immunoglobulin fraction eluted with the void volume and was later confirmed to be IgG by immunoelectrophoresis as described by Graber \& Burtin (1964). The IgG solution (containing IgG-anti-PMSG or IgG-anti-hCG) was concentrated by negative-pressure dialysis and centrifugation at $10000 \mathrm{~g}$ for $30 \mathrm{~min}$. Sterilization was effected by passage through $0.2 \mathrm{~mm}$ Sartorius Membrane Filter, type SM 16519 (Sartorius Filter Co., West Germany). The immunoglobulin solutions were then stored at $-20^{\circ} \mathrm{C}$ in $1 \mathrm{ml}$ aliquots containing $10 \mathrm{mg}$ IgG. Protein concentrations were determined spectrometrically at $280 \mathrm{~nm}$ (Beckman DB-GT, Grating Spectrophotometer).

The antibody titre was determined by the microhaemagglutination test of Boyden (1951) and found to be 1:4096 for PMSG and 1:6144 for hCG. The antibodies were analysed for specificity and cross-reaction by the gel precipitation method (Ouchterlony, 1962) and double counter-current immunoelectrophoresis. The cross-reactivities of the antisera were checked against hCG, hFSH, hLH and human prolactin for the PMSG antibody and against PMSG, hFSH, hLH and human prolactin for the hCG antibody. The purified antisera were highly specific, with anti-PMSG reacting only against PMSG and anti-hCG reacting only against hCG.

\section{Experiments}

Fifty-nine (59) female Wistar rats $(250-300 \mathrm{~g})$ were used. Each female was caged separately with a male until mating occurred (Day 1), as determined from vaginal smears every morning and afternoon. The male was then removed. Pregnant rats were assigned to one of 4 experimental groups.

Group I comprised 15 animals which received $4 \mathrm{mg} \mathrm{IgG-anti-PMSG} \mathrm{interperitoneally} \mathrm{for} 5$ days each morning between $08: 00$ and $08: 30 \mathrm{~h}$. Five of the animals (A) were injected from Day 6, five from Day 11 (B) and five from Day 16 (C).

At 5 days after the end of treatment, the animals in Groups IA and IB were bled and killed. One ovary and the uterus of each animal were fixed in $5 \%$ formol saline for histology. The other ovary was frozen for subsequent steroid extraction and assay. Animals in Group IC were allowed to go to term and litter. The number and weight of the fetuses was recorded.

Group II: 4 rats were injected with $10 \mathrm{mg} \mathrm{IgG-anti-PMSG} \mathrm{on} \mathrm{Day} \mathrm{6} \mathrm{(A),} \mathrm{Day} 11$ (B) or Day 16 (C) of gestation and the subgroups were treated in the same way as those in Group I.

Group III: the three subgroups of 4 rats each were treated as for Group I but each rat was injected with $10 \mathrm{mg}$ IgG-anti-hCG.

Group IV was the control group : 5 rats were killed on Day $16(\mathrm{~A}), 5$ on Day $21(\mathrm{~B})$ and the remaining 5 were allowed to litter (C). Five rats were treated with $10 \mathrm{mg}$ non-immune $\mathrm{IgG}$ for 5 days from Day 6 to serve as additional controls (D). These rats were killed on Day 16 and the ovaries and uterus were fixed in $5 \%$ formol saline for histology.

\section{Autopsy}

Histology. The formol saline-fixed ovaries and uteri were processed routinely for histology. Sections were cut at $7 \mu \mathrm{m}$ and stained with Ehrlich's haematoxylin and eosin. Corpora lutea, implantation sites, placentae and fetuses were studied by light microscopy.

Steroids. All reagents used for extraction and assay of steroids were Analar grade and were purchased from a variety of sources. Ovarian homogenates and plasma samples were ether-extracted as described by Gombe \& Oduor-Okelo (1977) for testosterone. Mean \pm s.e.m. recoveries for ovarian and plasma samples were $85 \pm 2$ and $96 \pm 2 \%$ respectively for progesterone and $94 \pm 3$ and $89 \pm 3 \%$ 
respectively for oestrogens. Progesterone and total unconjugated oestrogens were measured by radioimmunoassays. The antiserum to progesterone (B456 No. 6) was kindly donated by Dr R. B. Heap, Cambridge. The mean recovery of authentic progesterone $(25-1000 \mathrm{pg} / \mathrm{ml}$ stripped plasma) was $89 \cdot 6 \pm 2 \cdot 7 \%$ and the within-assay coefficient of variation was $5 \cdot 2 \%(n=12)$. The working range of the assay was $20-1000 \mathrm{pg}$. All plasma samples were assayed together and all tissue samples were assayed together but separately from the plasma samples. The antiserum to oestradiol-17 $\beta$ (S-52-S) was purchased from $\operatorname{Dr}$ G. E. Abrahams, California. This antiserum cross-reacts with oestradiol-17 $\beta$ $(40 \%)$, oestrone $(35 \%)$ and oestriol $(8 \%)$. Therefore the values given represent total unconjugated oestrogens. The recovery was $88 \cdot 3 \pm 2 \cdot 0 \%$ from 10 to $500 \mathrm{pg}$ authentic oestradiol-17 $\beta$ added to $1 \mathrm{ml}$ stripped plasma. The within-assay coefficient of variation was $5.4 \%(n=12)$ and the working range of the assay was $5-500 \mathrm{pg}$.

\section{Statistical tests}

The statistical significance of the difference between means was tested by Student's $t$ test and Duncan's new multiple range test.

\section{Localization of antigonadotrophic activity}

The site of activity of the IgG-anti-PMSG and IgG-anti-hCG was examined by immunofluorescence studies. Thin sections ( $4 \mathrm{~mm}$ ) of fresh rat placentae from all the 20 animals in control Group IV were frozen on microscope slides, previously cooled with solid $\mathrm{CO}_{2}$, with a freezing medium (OCT Compound, Lab-Tek. Products, Naperville, Illinois) and then stored at $-20^{\circ} \mathrm{C}$ until required. These were subsequently sectioned at $7 \mu \mathrm{m}$ on a cryostat set at $-26^{\circ} \mathrm{C}$. The sections were mounted on acidcleaned slides, dried in a cold stream of air in dry slide boxes at $4^{\circ} \mathrm{C}$, and wrapped in airtight polythene bags. Silica gel was used as a dessicant.

Fluorescein conjugation. The IgG-anti-PMSG, IgG-anti-hCG and non-immune IgG (100 mg) were each conjugated with fluorescein isothiocyanate (Isomer 1, Lot No. 9101581, Cockeyville, Maryland, U.S.A.) according to the method of Clark \& Sheppard (1963). Each conjugate was dialysed for $24 \mathrm{~h}$ against $0.01 \mathrm{M}$-sodium phosphate-buffer, $\mathrm{pH} 7.5$; then applied to an ion-exchange column containing diethyl aminoethyl cellulose (DE-52) pre-equilibrated with the above buffer to which $0.05 \mathrm{M}-\mathrm{NaCl}$ had been added. The conjugate was eluted from the column with $0.01 \mathrm{M}$-sodium phosphate buffer $(\mathrm{pH} 7 \cdot 5)$ to which increasing concentrations of $\mathrm{NaCl}$ solution $(0 \cdot 05,0 \cdot 1,0 \cdot 3,0 \cdot 5$ and $1.0 \mathrm{M}-\mathrm{NaCl}$ ) were added. Three peaks were obtained at salt concentrations of $0.05,0.3$ and $1.0 \mathrm{M}-\mathrm{NaCl}$. The fraction eluting with $0.3 \mathrm{M}-\mathrm{NaCl}$ was retained whilst the early and late fractions were discarded. The usable fraction was then concentrated by negative-pressure dialysis.

The protein concentration and the fluorescein/protein $(F / P)$ ratio were determined spectrometrically, according to the method of Brandtzaeg (1973), on a spectrometer (Beckman BD-GT Grating Spectrophotometer) used at $280 \mathrm{~nm}$ (for protein measurement) and $495 \mathrm{~nm}$ (for fluorescein measurement) respectively. The protein concentration was $20.7 \mathrm{mg} / 1 \mathrm{ml}$ for the antiserum to PMSG and $26.4 \mathrm{mg} / \mathrm{l} \mathrm{ml}$ for the antiserum to hCG. The corresponding F/P ratios were 5.2 and 6.4 . The conjugates were centrifuged at $10000 \mathrm{~g}$ for $1 \mathrm{~h}$, sterilized by millipore dialysis (see above) and stored.

Demonstration of fluorescence. The conjugates were tested at various dilutions to determine the optimal working dilution. The methods of Johnson \& Holborow (1973) were used. The placental sections were fixed for $1 \mathrm{~min}$ in ice-cold $\left(4^{\circ} \mathrm{C}\right) 40 \%$ ethyl alcohol, then transferred to sodium phosphate buffer $(0.01 \mathrm{M}, \mathrm{pH} 7.2)$ changed every $10 \mathrm{~min}$, and left for $30 \mathrm{~min}$. The slides were gently wiped with absorbent tissue paper and put into a humid chamber. Three drops of the respective fluorescent antibody were added over the tissue. After $30 \mathrm{~min}$, unbound fluorescent antibodies were washed off with sodium phosphate-buffered saline (PBS), $\mathrm{pH} 7 \cdot 2$, and the slides passed through three changes of the buffer in $45 \mathrm{~min}$. The slides were dried, mounted in $5 \%$ glycerol in PBS, and the edges of the mount sealed with nail polish. The slides were viewed with a Leitz Ortholux microscope with a 200-W HBO mercury lamp, a 3-mm BG12 transmission filter and a K510 barrier filter. Contiguous sections were 
processed for routine histology. Immunofluorescent controls were provided by mixing conjugated antibodies with excess antigens (hCG and PMSG), leaving overnight, and staining the placental sections as described above. A further control was provided by the use of non-immune, fluoresceinconjugated goat IgG.

\section{Results}

All the rats treated with anti-PMSG and anti-hCG remained in good health for the duration of the experiment. At autopsy an abundance of mesenteric fat was particularly noticeable. There were no signs of peritonitis.

\section{Litter size and weight}

The rats in Group IC all littered, the number of fetuses (58) and the fetal weight $(6 \cdot 8 \pm 0 \cdot 5$ (s.e.m.) g) being comparable to those of the controls in Group IVC $(n=47,6.9 \pm 0.4 \mathrm{~g})$. Only 1 rat in Group IIC gave birth to an apparently normal litter $(n=11,6 \cdot 6 \pm 0.4 \mathrm{~g})$. Two rats in Group IIIC gave birth: the number of fetuses (25) was normal but the mean \pm s.e.m. weight of the young (5.9 \pm $0.3 \mathrm{~g}$ ) was significantly $(P<0.05)$ less than that of controls (Group IVC).

Dead degenerating fetuses were removed on Day 26 post coitum from the 3 rats in Group IIC and the 2 in Group IIIC which did not litter.

\section{Histology}

Fetal. The conceptuses in Groups IA and IB appeared macroscopically normal, but definite degenerative changes were detectable in the placentae. These changes consisted of scattered necrotic foci of the giant cell layer and the adjoining spongy trophoblast (Pl. 1, Fig. 1). Congestion of the trophoblast was evident. The necrotic foci were invariably invaded by lymphocytes and neutrophils. In Groups IIA and IIIA fetal resorption was complete in 3 of the animals and nearly complete in the other, the implantation sites in the former were recognized histologically by small eosinophilic hyaline nodules surrounded by haemosiderin deposits (PI. 1, Fig. 2). There was partial fetal resorption in 2 of the Group IIB and IIIB rats and the other 2 contained dead but unresorbed fetuses. In all the rats the placentae were entirely necrotic and massively infiltrated by leucocytes (Pl. 1, Fig. 3).

The conceptuses in Group IVD were macroscopically and microscopically normal.

Ovarian. The CL of the animals in Groups IA, IB and IIA were histologically hyperaemic but otherwise were not different from those of rats in Groups IVA and IVB (PI. 1, Fig. 4). Group IIB rats also had apparently normal luteal cells although the CL were very congested. In Groups IVA and IIIB the CL were macroscopically normal but central necrosis (Pl. 1, Fig. 5), larger in the CL of IIIB animals, was apparent. The CL of the rats in Groups IIC and IIIC that did not litter and had dead fetuses in utero were macroscopically and microscopically normal, as were those of Group IVD animals treated with non-immune IgG.

\section{Steroid concentrations}

These are shown in Table 1. Compared with controls, ovarian progesterone concentrations were significantly higher in Groups IA, IB and IIIA, while plasma progesterone levels were significantly lower in Groups IIA, IIB, IIIA and IIIB. Plasma oestrogen concentrations were significantly higher in Group IIB animals than in those of Group IVB. The CL of the Group IIC and IIIC rats with dead fetuses appeared to contain normal amounts of progesterone. 
Table 1. The effect of treatment (mean \pm s.e.m.) of pregnant rats for 5 days with antibodies to PMSG and hCG on concentrations of progesterone and total oestrogens

\begin{tabular}{|c|c|c|c|c|c|c|}
\hline \multirow[b]{2}{*}{ Treatment } & \multirow[b]{2}{*}{ Group } & \multirow[b]{2}{*}{$\begin{array}{c}\text { No. of } \\
\text { rats }\end{array}$} & \multicolumn{2}{|c|}{ Progesterone } & \multicolumn{2}{|c|}{ Oestrogen } \\
\hline & & & $\begin{array}{c}\text { Ovarian } \\
(\mathrm{ng} / \mathrm{g})\end{array}$ & $\begin{array}{l}\text { Plasma } \\
(\mathrm{ng} / \mathrm{ml})\end{array}$ & $\begin{array}{l}\text { Ovarian } \\
\text { (ng/g) }\end{array}$ & $\begin{array}{l}\text { Plasna } \\
(\mathrm{pg} / \mathrm{ml})\end{array}$ \\
\hline \multicolumn{7}{|l|}{ Anti-PMSG, $4 \mathrm{mg} /$ day } \\
\hline -from Day 6 & IA & 5 & $444 \cdot 7 \pm 52 \cdot 5^{*}$ & $6 \cdot 1 \pm 1 \cdot 3$ & - & - \\
\hline -from Day 11 & IB & 5 & $309 \cdot 8 \pm 81 \cdot 5 *$ & $7 \cdot 1 \pm 0.9$ & - & - \\
\hline \multicolumn{7}{|l|}{ Anti-PMSG, $10 \mathrm{mg} /$ day } \\
\hline -from Day 6 & IIA & 4 & $199 \cdot 8 \pm 52 \cdot 1$ & $4.9 \pm 0.6^{*}$ & $15 \cdot 2 \pm 11 \cdot 0$ & $82 \cdot 3 \pm 24 \cdot 7$ \\
\hline —from Day 11 & IIB & 4 & $117 \cdot 4 \pm 34 \cdot 5$ & $5 \cdot 7 \pm 0 \cdot 6^{*}$ & $2 \cdot 0 \pm 1 \cdot 4$ & $118 \cdot 3 \pm 28 \cdot 3^{*}$ \\
\hline -from Day 16 & IIC & $3+$ & $94 \cdot 4 \pm 24 \cdot 3$ & $5 \cdot 6 \pm 1 \cdot 3$ & $0.8 \pm 0.2$ & $106 \cdot 7 \pm 63 \cdot 3$ \\
\hline \multicolumn{7}{|l|}{ Anti-hCG, $10 \mathrm{mg} / \mathrm{day}$} \\
\hline -from Day 6 & IIIA & 4 & $286 \cdot 4 \pm 125 \cdot 5^{*}$ & $4.9 \pm 0.4^{*}$ & $5 \cdot 0 \pm 0 \cdot 1$ & $175 \cdot 0 \pm 86 \cdot 7$ \\
\hline -from Day 11 & IIIB & 4 & $125 \cdot 8 \pm 37 \cdot 4$ & $3 \cdot 0 \pm 1 \cdot 6^{*}$ & $3 \cdot 0 \pm 1 \cdot 2$ & $88 \cdot 8 \pm 24 \cdot 1$ \\
\hline -from Day 16 & IIIC & $2 \dagger$ & $106 \cdot 7$ & $3 \cdot 5$ & 0.4 & $91 \cdot 5$ \\
\hline \multicolumn{7}{|l|}{ None } \\
\hline Killed Day 11 & IVA & 5 & $96 \cdot 7 \pm 22 \cdot 0$ & $7 \cdot 2 \pm 1 \cdot 4$ & $8 \cdot 6 \pm 1 \cdot 5$ & $81 \cdot 6 \pm 24 \cdot 7$ \\
\hline Killed Day 16 & IVB & 5 & $100 \cdot 3 \pm 23 \cdot 5$ & $8.4 \pm 0.9$ & $3 \cdot 0 \pm 1 \cdot 6$ & $55.8 \pm 12.8$ \\
\hline
\end{tabular}

All rats in Group IVC were allowed to litter, therefore no steroid levels are available.

* These values are significantly different from those of corresponding control groups, $P<0.05$.

$f$ Animals with dead fetuses at autopsy (see text).

\section{Immunofluorescence}

The optimal working dilution was $1: 64$ for IgG-anti-hCG and 1:96 for IgG-anti-PMSG. At these dilutions, no immunofluorescence was visible in the control animals. The anti-hCG fluorescein conjugate stained the rat placentae positively (see Plate 2). The greatest immunofluorescent material was present at the feto-maternal junction on the giant cells and outermost chorionic cells (Pl. 2, Fig. 7). Under oil-immersion the region consisted of very small stained globules. Some positive staining was evident in the spongy trophoblast, but none was seen in the labyrinthine zone. The maternal myometrium showed no staining, whilst the positive staining in the endometrium was restricted to the area adjacent to the feto-maternal junction, and was of very low intensity. The anti-PMSG-fluorescein conjugate stained the same areas as did the anti-hCG conjugate except that the intensity of immunofluorescence was much weaker (Pl. 2, Fig. 8). Staining with the non-immune IgG-fluorescein conjugate was not observed anywhere in the placenta (Pl. 2, Fig. 9).

\section{Discussion}

In this study we have shown that the response of pregnant rats to antigonadotrophic activity is dependent on the dose and stage of gestation. Loewit et al. (1969) found that antiserum to LH caused fetal resorption in rats before mid-pregnancy and thereafter had no effect. We have shown that resorption could still be obtained after mid-pregnancy provided that the dose of antibody was high enough. We have further shown that even when resorption did not occur, some damage to the placenta was always evident. Low levels of anti-PMSG ( $4 \mathrm{mg} /$ day), although insufficient to kill the conceptuses, caused observable necrosis of the outermost trophoblastic cells at a time when luteal function was apparently enhanced. The observation that the trophoblastic damage increased towards the deeper layers with increase in dose and stage of gestation is consonant with progressive maternal immune 
attack from superficial to deeper tissues. That the anti-gonadotrophins did not always cause fetal death and resorption after Day 16 can be explained in several ways: first, that the treatment period was not long enough to allow full immune attack; secondly, that there is a decrease in placental gonadotrophin/gonadotrophin receptors with advancing gestation; or thirdly, that both processes are operative.

It might be argued that, if placental gonadotrophin were immunosuppressive, the general immunity of pregnant animals would be affected. However for immunosuppression to take place the organ being protected must have receptor sites for gonadotrophins. Further, if the gonadotrophins were produced and used in situ there would be little interference with general immune reactions, even if other tissues had appropriate receptors. There is little doubt from this and the work of others that fetal membranes have receptors for gonadotrophins. The present immunofluorescent studies support this observation. Gonadotrophin (hCG/PMSG)-like substances exist at the feto-maternal junction of the rat placenta. This rat placental gonadotrophin is present in highest concentrations in the region of the giant and chorionic cells, and decreases in quantity towards the deeper placental tissue. This material adheres to the cells in a particulate manner and only negligible quantities are present on the apposed maternal endometrium. These observations lead to the conclusion that the placental gonadotrophin-like material is synthesized by the chorionic cells and is then complexed with cell membrane receptors of the outermost chorionic and giant cells. The specificity of the antibodies used in these experiments indicates that the gonadotrophin is unlikely to be a placental lactogen.

\section{EXPLANATION OF PLATES}

\section{PLATE 1}

Fig. 1. Section of the placenta of a rat from Group IA (4 mg IgG-anti-PMSG from Day 6) showing the congestion of blood vessels (b), scattered necrotic foci of the giant cells ( $g$ ) and necrosis of the spongy zone (n). $\times 88$.

Fig. 2. Section of the implantation site (si) of a rat from Group IIA (10 mg IgG-anti-PMSG from Day 6) showing the lack of fetal tissues, hyaline nodules $(\mathrm{hn})$ and haemosiderin deposits $(\mathrm{hd}) . \times 88$.

Fig. 3. Section of the spongy zone of the placenta of a Group IIB rat (10 mg IgG-anti-PMSG from Day 11) showing the necrosis and lymphocytic $(\mathrm{lm})$ invasion. $\times 140$.

Fig. 4. A corpus luteum from a normal control rat (Group IVB) killed on Day 16 showing the well developed luteal cells (lc). $\times 140$.

Fig. 5. A corpus luteum from a rat killed on Day 16 after treatment with $10 \mathrm{mg}$ IgG-anti-hCG (Group IIIB) showing the reasonably well developed luteal cells $(\mathrm{lc})$ and the central necrosis $(\mathrm{cn}) . \times 140$.

\section{PLATE 2}

Sections of the placenta of a control rat (Group IVA) at Day 11 of gestation. $\times 100$.

Fig. 6. Light micrograph showing the spongy zone (s), giant cells (g), blood vessels (b), maternal endometrium (e) and maternal myometrium $(\mathrm{m})$.

Fig. 7. Section treated with anti-hCG-fluorescein conjugate showing the intensity of immunofluorescence in the region of giant cells and the outermost chorionic cells.

Fig. 8. Section treated with anti-PMSG-fluorescein conjugate showing a distribution of fluorescence similar to, but of lower intensity than, that in Fig. 2.

Fig. 9. Section treated with non-immune IgG-fluorescein conjugate. Note the absence of giant and chorionic cell staining and only light background staining in the top left hand corner. 
PLATE 1
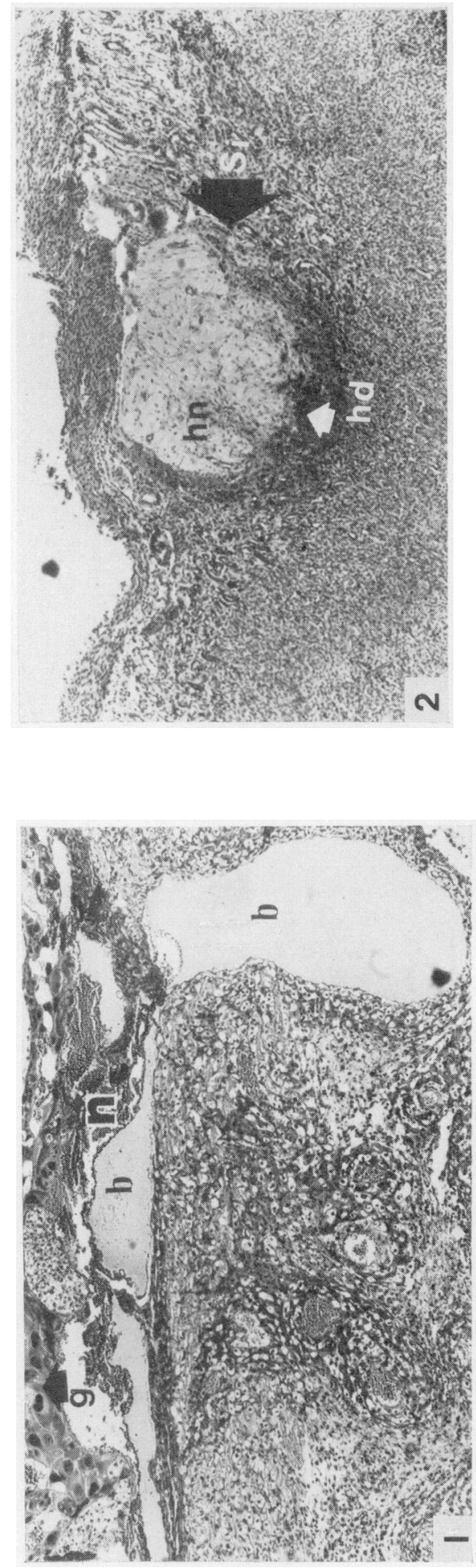
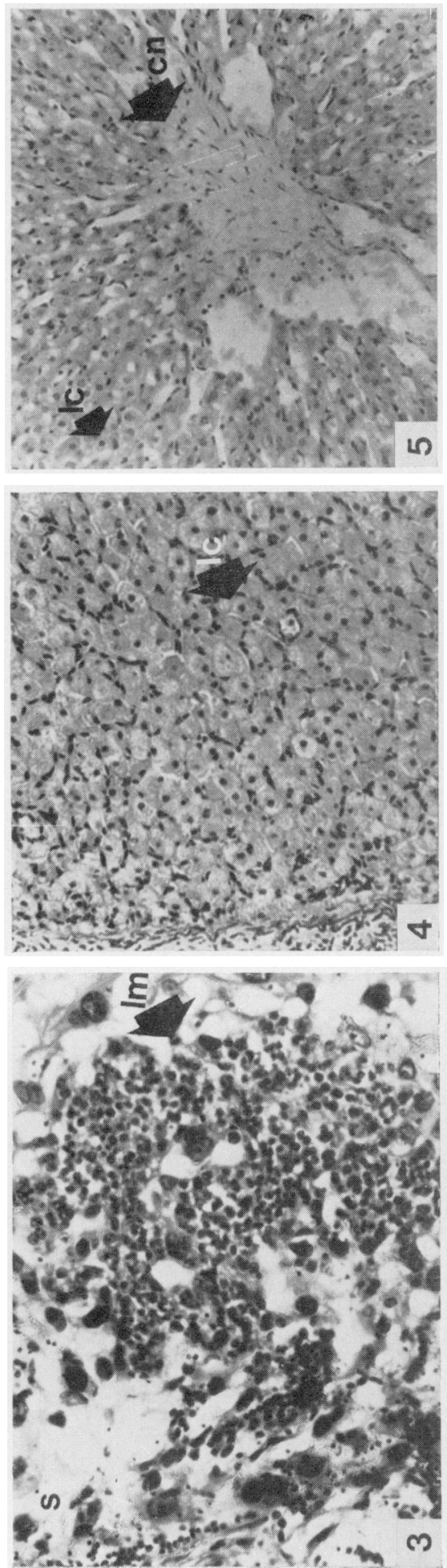

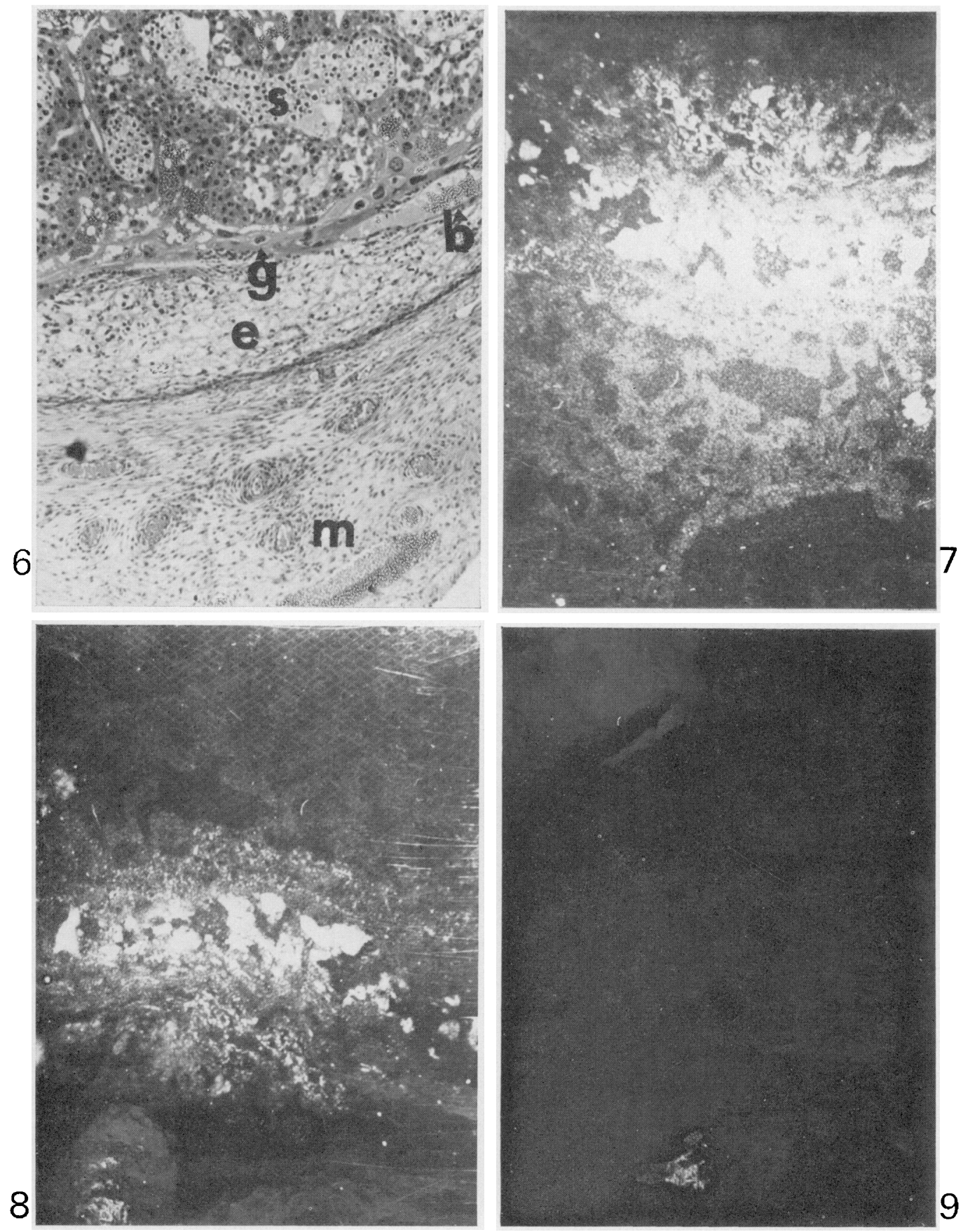
Loewit et al. (1969) contended that fetal resorption in rats treated with anti-LH was due to decreased ovarian function, the implication being that there was a fall in ovarian progesterone and thereby plasma progesterone. Our results indicate that, from mid-gestation onwards, anti-PMSG and anti-hCG caused a slight but significant fall in plasma progesterone. This was, however, concomitant with slightly elevated ovarian progesterone concentrations. Ovarian progesterone concentration was still quite high on Days 21 and 26 of gestation in Groups IIC and IIIC, the latter time being long after the fetuses had been resorbed. The decreasing plasma progesterone concentrations could be explained by an increased clearance in treated animals, and alteration of the clearance rate for steroids is suggested by the high oestrogen values in plasma when ovarian concentrations are quite low. Preliminary evidence (unpublished) indicates that there are changes in clearance rate in the antibodytreated animals. We do not at present know why antiserum to PMSG (especially in low doses) and antiserum to $\mathrm{hCH}$ should apparently stimulate ovarian progesterone synthesis.

We conclude that the rat placenta produces a chorionic gonadotrophin, in situ, which coats the outer trophoblastic cells and thereby protects the fetus from maternal immunological attack. The ovarian changes are probably independent.

We thank the Dean's Committee of the University of Nairobi for a research grant; Professor Houba, W.H.O. Immunology Centre, Kenyatta Hospital, for allowing us to use the laboratory facilities; Dr Jack Doyle, Dr Z. Ahamed and Mr D. Alliangana for advice and assistance; and Dr D. Oduor-Okelo for partly processing and advising on histological sections.

\section{References}

Amoroso, E.C. \& Perry, J.S. (1975) The existence during gestation of an immunological buffer zone at the interface between maternal and foetal tissue. Phil. Trans. R. Soc. Lond., B 271, 343-361.

Boyden, S.V. (195I) The absorption of protein on erythrocytes treated with tannic acid and subsequent haemagglutination with anti protein antisera. J. exp. Med. 93, 197-203.

Brandtzaeg, P. (1973) Conjugates of immunoglobulin $\mathrm{G}$ with different fluorochromes. I. Characterization by anionic-exchange chromatography. Scand. $J$. Immun. 2, 273-290.

Clark, H.F. \& Sheppard, C.C. (1963) A dialysis technique for preparing fluorescent antibody. Virology 20, 642-644.

Gombe, S. \& Oduor-OKelo, D. (1977) Effect of temperature and relative humidity on plasma and gonadal testosterone concentrations in camels (Camelus dromedarius). J. Reprod. Fert. 50, 107-108.
Graber, P. \& BURTIN, P. (1964) Immunoelectrophoresis Analysis. Elsevier Pub. Company, London.

Johnson, G.D. \& Holborow, E.J. (1973) Immunofluorescence. In Handbook of Experimental Immunology, Chap. 16, pp. 571-596. Ed. D. M. Weir. Blackwell, Oxford.

Loewit, K. \& Laurence, K.A. (1969) Termination of pregnancy in the rat with rabbit anti-bovine luteinizing hormone serum. Fert. Steril. 20, 679-688.

Loewit, K., Badawy, S. \& Laurence, K.A. (1969) Alteration of corpus luteum function in the pregnant rat by anti-luteinizing hormone serum. Endocrinology 84, 244-291.

OUCHTERLONY, O. (1962) Diffusion in gel methods for immunological analysis. Prog. Allergy 6, 30-154.

Received 20 October 1977 